\title{
Sequential randomised and double blind trial of promethazine prophylaxis against early anaphylactic reactions to antivenom for bothrops snake bites
}

\author{
Hui Wen Fan, Luiz F Marcopito, João Luiz C Cardoso, Francisco O S França, Ceila M S Malaque, \\ Ronnei A Ferrari, Robert David G Theakston, David A Warrell
}

\begin{abstract}
Objective To investigate the efficacy of the $\mathrm{H}_{1}$ antihistamine promethazine against early anaphylactic reactions to antivenom.

Design Sequential randomised, double blind, placebo controlled trial.

Setting Public hospital in a venom research institute, São Paulo, Brazil.

Participants 101 patients requiring antivenom treatment after being bitten by bothrops snakes. Intervention Intramuscular injection of promethazine $(25 \mathrm{mg}$ for adults and $0.5 / \mathrm{kg}$ for children) or placebo given 15-20 min before starting intravenous infusion of antivenom.

Main outcome measures Incidence and severity of anaphylactic reactions occurring within 24 hours after antivenom.

Results Reactions occurred in 12 of 49 patients treated with promethazine (24\%) and in 13 of 52 given placebo (25\%); most were mild or moderate. Continuous sequential analysis indicated that the study could be interrupted at the 22nd untied pair, without preference for promethazine or placebo. Conclusion Prophylaxis with promethazine does not prevent early reactions. Patients should be observed carefully during antivenom infusion and the subsequent few hours.
\end{abstract}

\section{Introduction}

About 20000 snake bites are reported yearly in Brazil. Antivenom (hyperimmune immunoglobulin), the only specific antidote, may cause anaphylactic or anaphylactoid reactions, ${ }^{2-5}$ depending on the type of antivenom, dose, mode of administration, and previous exposure to animal proteins. ${ }^{6}$ Adverse reactions cannot be predicted by sensitivity tests, ${ }^{7}$ and the reported frequency is as high as $87 \% .{ }^{3}$ Urticaria, angio-oedema, and gastrointestinal symptoms are the commonest manifestations, but bronchospasm and shock may be fatal.

Prophylaxis with antihistamines $\left(\mathrm{H}_{1}\right.$ blockers with or without $\mathrm{H}_{2}$ blockers) has been proposed..$^{8-10}$ However, there have been no properly controlled studies. The aim of this study was to test whether intramuscular promethazine, a widely recommended prophylactic treatment in Brazil ${ }^{11}$ and other countries, was effective in preventing early anaphylactic reactions.

\section{Participants and methods}

We recruited consecutive patients over 2 years old attending Hospital Vital Brazil, Instituto Butantan, São Paulo, Brazil, after being bitten by bothrops snakes. We excluded patients who had received antihistamine, corticosteroids, or antivenom before reaching hospital, pregnant women, and patients with severe haemorrhage, hypotension, or acute renal failure. ${ }^{1}$ Oral informed consent was obtained.

This study was a randomised, double blind, placebo controlled trial followed by sequential analysis. To ensure an equal number of patients in each group and to avoid breaking the code we used block randomisation. ${ }^{12}{ }^{13}$ Identical ampoules were labelled in numerical order and arranged in randomised blocks of six, each block containing three promethazine and three placebo ampoules.

Patients received a deep intramuscular injection of placebo or $25 \mathrm{mg}$ promethazine $(2 \mathrm{ml}$ for adults and $0.04 \mathrm{ml} / \mathrm{kg}$ (representing $0.5 \mathrm{mg} / \mathrm{kg}$ ) for children under $50 \mathrm{~kg}$ ) into the deltoid muscle 15-20 minutes before antivenom therapy. Then, according to clinical severity, either 40 or $80 \mathrm{ml}$ of bothrops antivenom (Instituto Butantan, Fundação Ezequiel Dias, or Instituto Vital Brazil) diluted 1:5 in saline, was given intravenously over about 20 or 40 minutes.

Patients were observed during infusion with antivenom and for 24 hours subsequently. Early reactions were recorded as mild (restricted urticaria, facial flush, dry cough, and hoarseness), moderate (extensive urticaria, nausea, vomiting, abdominal cramps, diarrhoea, and bronchospasm), or severe (glottal oedema, hypotension, and shock).

\section{Statistical analysis}

We compared treatments by continuous sequential analysis $^{14}$ using the open scheme for explanatory approach..$^{15}$ Proportion of success (no reaction) with placebo $\left(\mathrm{p}_{1}\right)$ was estimated as 0.70 and that with promethazine $\left(\mathrm{p}_{2}\right)$ as 0.875 (25\% improvement for promethazine group); type I error $(\alpha)=0.10$, type II error $(\beta)=0.05$. A figure was constructed with a horizontal axis representing the number of untied pairs $(n)$, a vertical axis $(y)$ representing excess of preferences for promethazine or placebo, two external boundaries $(U$ and $L)$ limiting preference zones, and two internal boundaries $(M$ and $M$ ) limiting the no preference zone.

Pairs consisted of one patient from each group in order of entrance to the study. Only untied pairs (reaction occurring in a patient of one group but not in the other) were taken into account. An arbitrary value of +1 was given for pairs in which preference was for promethazine (no reaction with promethazine and reaction with placebo) and -1 when the preference was for placebo (reaction with promethazine and no reaction with placebo). A diagonal line was drawn in each square of the sequential scheme, and the study was interrupted when one boundary was reached (see $B M J$ 's website for more information).

\author{
Hospital Vital \\ Brazil, Instituto \\ Butantan, Avenue \\ Vital Brazil 1500, \\ 05503-900, São \\ Paulo, Brazil \\ Hui Wen Fan, \\ doctor \\ João Luiz C \\ Cardoso, \\ doctor \\ Francisco O S \\ França, \\ doctor \\ Ceila M S Malaque, \\ doctor \\ Ronnei A Ferrari, \\ doctor \\ Division of \\ Epidemiology, \\ Escola Paulista de \\ Medicina, Unifesp, \\ 04039-032, São \\ Paulo, Brazil \\ Luiz F Marcopito, \\ associate professor \\ Alistair Reid Venom \\ Research Unit, \\ Liverpool School of \\ Tropical Medicine, \\ Pembroke Place, \\ Liverpool L3 5QA \\ Robert David G \\ Theakston, \\ associate professor \\ continued over
}

BMJ 1999;318:1451-2

website

extra

Further details of the methods and a figure are available on the BMJ's website

www.bmj.com 
Centre for Tropical Medicine,

University of

Oxford, John

Radcliffe Hospital,

Headington,

Oxford OX3 9DU

David A Warrell,

associate professor

Correspondence to:

Dr H W Fan

fhui@uol.com.br

BMJ 1999;318:1452-146

\begin{tabular}{lcc}
\hline Yes & 7 & 6 \\
\hline No & 42 & 46 \\
\hline Blood clotting & 19 & 24 \\
\hline Unclottable & 30 & 28 \\
\hline Clottable & & \\
\hline Severity of envenoming & 36 & 40 \\
\hline Mild & 13 & 12 \\
\hline Moderate & 24 & \\
\hline Antivenom & 19 & 17 \\
\hline Instituto Vital Brazil & 6 & 12 \\
\hline Instituto Butantan & & \\
\hline Fundação Ezequiel Dias & 25 & 19 \\
\hline Speed of infusion (ml/min) & 23 & 2 \\
\hline$<1.6$ & 1 &
\end{tabular}

Based on a probability of obtaining an untied pair $\varphi=0.35$ and finishing the study at the 20th untied pair if there were no preferences, we calculated the sample size as $\mathrm{n}=$ minimum number of untied pairs $\times 2$ / probability of obtaining a untied pair, where $n=114$.

A database was constructed with Epi-Info 6.0 software. We used the $\chi^{2}$ test for trend, $\chi^{2}$ test for determining heterogeneity between proportions, and Student's $t$ or non-parametric Kruskall-Wallis tests for comparing means.

\section{Results}

Between March 1994 and June 1995 we recruited 101 patients. Twenty three patients were excluded (13 had received antivenom and 10 antihistamine or steroids

Table 2 Distribution of early anaphylactic reactions according to treatment

\begin{tabular}{lccc} 
Group & No of patients & No (\%) with reaction & $\mathbf{9 5 \% ~ C l ~ ( \% ) ~}$ \\
\hline Promethazine & 49 & $12(24)$ & 13 to 39 \\
\hline Placebo & 52 & $13(25)$ & 14 to 39 \\
\hline Total & 101 & $25(25)$ & 17 to 34
\end{tabular}

Table 3 Early anaphylactic reactions according to the type of antivenom administered

\begin{tabular}{lcccc} 
Type of antivenom & Promethazine & Placebo & Total & P value \\
\hline Instituto Vital Brazil & 6 & 3 & 9 & \\
\hline Instituto Butantan & 6 & 5 & 11 & 0.432 \\
\hline Fundação Ezequiel Dias & 0 & 5 & 5 & \\
\hline Total & 12 & 13 & 25 &
\end{tabular}

${ }^{*} \chi^{2}$ for heterogeneity $=6.06, P=0.432$.

Table 4 Severity and clinical manifestations of early anaphylactic reactions

\begin{tabular}{lccc} 
Severity & Promethazine & Placebo & Total \\
\hline Mild & 8 & 5 & 13 \\
\hline Moderate & 3 & 7 & 10 \\
\hline Severe & 1 & 1 & 2 \\
\hline Total & 12 & 13 & 25 \\
\hline
\end{tabular}

$\chi^{2}$ for trend=1.12, $P=0.29$. before admission, nine had no symptoms of envenoming, and two were pregnant.)

Forty nine patients received promethazine and 52 placebo. Both groups were similar at baseline (table 1). Early anaphylactic reactions occurred in 25 of 101 patients. All responded promptly to adrenaline. Three other patients had pyrogenic reactions which were treated symptomatically.

Of the 25 patients who developed reactions, 12 had received prophylactic promethazine and 13 placebo (table 2). There were no differences in the type of antivenom administered (table 3 ) or the severity of reaction (table 4) between the two groups. Two patients had severe reactions: one developed laryngeal oedema and stridor (promethazine group) and one hypotension (placebo group). Nine patients given promethazine developed reactions during antivenom infusion compared with eight given placebo $(\mathrm{P}=0.67)$. The mean (SD) time after starting the infusion that the reaction occurred was 28.1 (16.2) $\mathrm{min}$ for promethazine and 25.0 (19.1) $\mathrm{min}$ for placebo $(\mathrm{P}=0.66)$. Anaphylaxis occurred 1-2 hours after the end of antivenom infusion in three patients given promethazine and five given placebo.

Construction of pairs and sequential analysis

There were 22 untied pairs among the 101 patients. A line was plotted showing the sum of the scores for successive pairs. The study was finished when the middle boundary was reached at the 22nd untied pair, indicating no difference between promethazine or placebo (see figure on BMJ's website).

\section{Discussion}

Reactions to antivenom remain common despite improvements in manufacturing processes. ${ }^{2-7}$ Prophylaxis is therefore important. ${ }^{4}{ }^{8-10} \mathrm{H}_{1}$ and $\mathrm{H}_{2}$ antihistamines, corticosteroids, and adrenaline have been recommended based on anecdotal experience, ${ }^{9}$ 10 $16-19$ but no prospective controlled trials have been reported.

We tested intramuscular promethazine because it is routinely used as prophylaxis in many countries. Its efficacy needed to be proved as it can cause complications, such as sedation or anticholinergic effects, that simulate or conceal important symptoms of envenoming. We found that intramuscular promethazine given 15-20 min before the start of bothrops antivenom did not prevent early anaphylactic reactions. This result cannot be attributed to the time of injection as adequate levels of promethazine would have been circulating by the time the antivenom was administered. ${ }^{20}$ However, promethazine does not block $\mathrm{H}_{2}$ receptors, which may be important in anaphylaxis. ${ }^{21}$

Most reactions (68\%) occurred during antivenom infusion. Patients should therefore be observed during administration and for at least 2 hours subsequently. Early anaphylactic reactions are promptly reversed by adrenaline. $^{4}$

We thank the nursing staff of Hospital Vital Brazil, Instituto Butantan, São Paulo, for help with the patients.

Contributors: HWF participated in the formulation of the primary study hypothesis, discussed core ideas, and participated in the protocol design, data collection, analysis, and writing the paper. LFM discussed the core ideas, designed the protocol, and participated in the statistical analysis and interpretation of the data and editing the paper. JLCC initiated the research, discussed core ideas and interpretation of the findings, 
participated in data collection, and contributed to the paper FOSF participated in the design and execution of the study, collected data, and discussed the interpretation of the findings. CMSM initiated the project, discussed ethical issues of the study and its design, collected data, and contributed to the paper. RAF participated in study design, data collection, and interpretation of results and contributed to the paper. RDGT initiated the formulation of the primary study hypothesis, discussed core ideas, and participated in the protocol design, analysis, and interpretation of the data and editing the paper. DAW initiated and coordinated the formulation of the main hypothesis, discussed core issues, participated in the design of the protocol, discussed the interpretation of the findings, and participated in the writing of the paper.

Funding: Promethazine and placebo were donated by Rhodia Farma Ltd. The study was supported by the Science and Technology for Development Programme of the European Community (Contract No TS3-CT91-0024).

Competing interests: None declared.

1 Fan HW, Cardoso JLC. Clinical toxicology of snake bites in South America. In: Meier J, White J, eds. Handbook of clinical toxicology of animal America. In: Meier J, White J, eds. Handbook of clinical tox:

2 Warrell DA, Looareesuwan S, Theakston RDG, Philips RE, Chanthavanish P, Viravan P, et al. Randomised comparative trial of three monospecific antivenoms for bites by the Malayan pit viper (Calloselasma rhodostoma) in southern Thailand: clinical and laboratory correlations. Am J Trop Med Hyg 1986;35:1235-47.

3 Cardoso JLC, Fan HW, Franca FOS, Jorge MT, Leite RP, Nishioka SA, et al. Randomized comparative trial of three antivenoms in the treatment of envenoming by lance-headed vipers (Bothrops jararaca) in São Paulo, Brazil. QJMed 1993;86:315-25.

4 Warrell DA, Davidson NMcD, Greenwood BM, Ormerod LD, Pope HM, Watkins BJ, et al. Poisoning by bite of the saw-scaled or caper viper (Echis carinatus) in Nigeria. QJ Med 1977;46:33-42.

5 Moran NF, Newman WJ, Theakston RD, Warrell DA, Wilkinson D. High incidence of early anaphylactoid reaction to SAIMR polyvalent snake antivenom. Trans R Soc Trop Med Hyg 1998,92:69-70.

6 World Health Organisation. Progress and characterization of venoms and standardization of antivenoms. WHO Offset Publication. Geneva: WHO, 1981:1-4. (No 58.)

7 Malasit P, Warrell DA, Chanthavanich AP, Viravan C, Mongkolsapaya J, Singhthong B, et al. Prediction, prevention, and mechanism of early (anaphylactic) antivenom reactions in victims of snake bites. $B M J$ $1986 ; 292: 17-20$
Key messages

- Antivenom therapy may cause early anaphylactic reactions

- Various drugs are used to prevent reactions, but none have been tested in randomised controlled studies

- This study showed that promethazine is not better than placebo at preventing early reactions

- Although most reactions are mild or moderate, trials of other drugs should be done to reduce frequency of anaphylaxis

8 Sutherland SK, Lovering KE. Use and adverse reactions over a 12-month period in Australia and Papua New Guinea. Med J Aust 1979;2:671-4.

9 Brian MJ, Vince JD. Treatment and outcome of venomous snake bite in children at Port Moresby General Hospital, Papua New Guinea. Trans $R$ Soc Trop Med Hyg 1987;81:850-2.

10 Cupo P, Azevedo-Marques MM, Menezes JB, Hering SE. Reações es de hipersensibilidade imediatas após uso intravenoso de soros antivenenos: valor prognóstico dos testes de sensibilidade intradérmicos. Rev Inst Med Trop São Paulo 1991;33:115-22.

11 Ministério da Saúde. Manual de diagnóstico e tratamento dos acidentes por animais peçonhentos. Brasilia: Fundação Nacional de Saúde, 1998.

12 Pocock SJ. Methods of randomization. In: Clinical trials. Chichester: John Wiley, 1983:66-89.

13 Armitage P. Pairing and randomization. Sequential experimentation. In Sequential medical trials. Oxford: Blackwell Scientific, 1972:21-3.

14 Wald A. Sequential analysis. New York: John Wiley, 1947.

15 Schwartz D, Flamant R, Lellouch J. Sequential trials. In: Clinical trials London: Academic Press, 1980:149-73.

16 Sutherland SK. Antivenom use in Australia. Premedication, adverse reactions and the use of venom detection kits. Med J Aust 1992;157:734-9.

17 Sutherland SK. Premedication before antivenom therapy. Med J Aust 1991;155:722.

18 Ford RM. Premedication before antivenom therapy. Med J Aust 1992;156:223.

19 Tiballs J. Premedication for snake antivenom. Med J Aust 1994;160:4-7.

20 Schwinghammer TL, Juhl P, Dittert LW, Melethil SK, Kroboth FJ, Chung VS. Comparison of the bioavailability of oral, rectal and intramuscula promethazine. Biopharmaceutics and Drug Disposition 1984;5:85-94.

21 Dachman WD, Bedarida G, Blaschke TF, Hoffman BB. Histamineinduced venodilation in human beings involves both $\mathrm{H}_{1}$ and $\mathrm{H}_{2}$ receptor subtypes. J Allergy Clin Immunol 1994;93:606-14.

\title{
The nuclear industry family study: linkage of occupational exposures to reproduction and child health
}

\author{
Noreen Maconochie, Pat Doyle, Eve Roman, Graham Davies, Peter G Smith, Valerie Beral
}

Concern about high rates of leukaemia and nonHodgkin's lymphoma among children and young adults living near certain nuclear establishments in the United Kingdom has led to a series of population based case-control studies. ${ }^{12}$ All these studies have investigated the possibility that the excesses were related to parental employment in those establishments, but the statistical power to detect anything other than extreme associations was very low owing to the rarity of employment in the nuclear industry (coupled with the rarity of the outcome). Moreover, if harmful parental occupational exposures were to exist it is unlikely that their effect would be restricted to cancer among workers' children; such exposures might be expected to influence a broader spectrum of reproductive problems, including infertility, miscarriage, and congenital malformations. These other aspects of reproduction remain largely unexplored.

The nuclear industry family study was set up to examine the occupational histories of a large cohort of nuclear industry workers in relation to all aspects of their reproduction and children's health. A full report of the methods is available on the BMJ's website.

\section{Subjects, methods, and results}

The survey population consisted of all employees of the Atomic Energy Authority, the Atomic Weapons Establishment, and British Nuclear Fuels who were in service at the time of the study, between 1993 and 1996 (8100, 6610, and 15550 workers respectively). Also included were past employees of the Atomic Energy Authority and British Nuclear Fuels who were aged under 75 years and who had an active or preserved pension administered by their joint pensions administration office (9678 and 6458 workers respectively). Of the survey population, $78 \%$ was male (36 342 workers).

Postal questionnaires were used to collect details of all reproductive attempts and the health of any children. Questions relating to periods of infertility were also included. Medical outcomes of interest were validated, with appropriate permission, by using clinical notes. Date of conception was estimated as the date of the end of pregnancy, minus gestational age, plus 14 days. Gestation was estimated as 40 weeks for most liveborn children (36 weeks or 28 weeks if
Papers p 1443 Correspondence to: Dr Maconochie n.maconochie@ lshtm.ac.uk continued over

BMJ 1999;318:1453-4 website extra

A full report of the methods of the study is available on the BMJ's website

www.bmj.com 